\title{
What are the impacts of bias correction on future drought projections?
}

\author{
Fiona Johnson \\ University of New South Wales, Sydney, Australia* \\ Ashish Sharma \\ University of New South Wales, Sydney, Australia
}

2

Corresponding author address: Fiona Johnson, School of Civil and Environmental Engineering, University of New South Wales

Kensington, New South Wales, 2052

Phone: +61 293859769

E-mail: f.johnson@unsw.edu.au 


\section{Abstract}

2 It is expected that anthropogenic greenhouse gas emissions will continue to change our

3 climate, and in turn the characteristics of future drought.. Assessments of the risks of future

4 droughts, when at a global or a continental scale, are often based on simulations from General

5 Circulation Models (GCMs). When raw GCM simulations are used, it is assumed that the

6 future deviations from modelled historical climatology represent the future drought. On the

7 other hand, it is known that raw GCM simulations are significantly biased for the variables

8 that affect hydrology and a correction is needed before assessments can be performed. We

9 investigate here whether drought assessments based on raw GCM simulations are biased and

10 the typical extent of this bias. Our assessment is based on the use of monthly precipitation

11 data from 18 CMIP3 GCMs, two popular bias correction alternatives and Australia as the

12 study domain. A number of different precipitation drought attributes have been assessed.

13 These include the Standardized Precipitation Index (SPI), multi-year rainfall statistics and a

14 drought vulnerability statistic that measures the maximum deviation of a time series from its

15 mean.

16 We find significant differences between droughts assessments using raw GCM simulations

17 and using bias corrected sequences. Large increases in drought frequencies are projected for

18 some parts of Australia. Both bias correction methods moderate these increases. This result is

19 consistent across the three different drought statistics. The bias corrected drought projections

20 also generally have slightly more agreement (smaller range of future changes) across the

21 GCMs compared to the raw projections, which is a promising result for attempting to reduce

22 model structural uncertainty. What this study shows is raw model simulations can lead to

23 incorrect drought assessments even at continental scales and bias corrections should be

24 applied. 


\section{Keywords}

2 Drought; General Circulation Model; bias correction 


\section{1. Introduction}

2 Anthropogenic climate change is now assessed as being "extremely likely" and is expected to

3 lead to detrimental effects for human and natural systems both at regional and global scales

4 (IPCC, 2013). One of the areas of concern is the impact of these changes on water resources

5 systems (Jiménez Cisneros et al., 2014), particularly for parts of the world where water

6 resources are already stressed due to population pressures, technological change and the

7 variability introduced by large scale natural climate drivers (Vörösmarty et al., 2010).

8 General Circulation Models (GCMs) are one method of assessing the likely impacts of

9 increasing greenhouse gas concentrations on natural and human systems. Despite the skill of

10 GCMs at a global scale, there remain concerns about their ability to model regional scale

11 impacts (Fowler et al., 2007a) and to represent certain features of the climate system, such as

12 precipitation (Chan et al., 2013), which form an important input to the modeling of water

13 resources systems (Maraun et al., 2010).

14 Techniques to overcome the weaknesses of GCMs to answer the particular questions of impact to scientists are based on the assumption that some regional scale changes do not create global scale feedbacks and therefore may be corrected outside of the modeling of the

17 GCM without affecting the accuracy of the global scale simulations (Pitman et al., 2012).

18 Methods that correct GCM simulations at a regional scale include dynamical downscaling

19 (regional climate modeling) or statistical downscaling. Given the significant differences in

20 GCM simulated fields compared to observations, there is often a need for a pre-processing

21 step before statistical or dynamic downscaling approaches can be used. This pre-processing

22 step is referred to as bias correction, whereby the GCM or regional climate model results

23 representing the current climate are corrected to match observations. The bias correction model over the historical period is assumed to be the same in future simulations, and can 
1 therefore be used to obtain the future projections (Buser et al., 2009). Bias correction has

2 been shown to be a simple and effective method that can be quickly be applied over large

3 areas, to multiple models or as pre or post-processing step for more sophisticated

4 downscaling methods (Chen et al., 2013; Gudmundsson et al., 2012; Ines and Hansen, 2006;

5 Johnson and Sharma, 2012; Li et al., 2010; Piani et al., 2010; Teutschbein and Seibert, 2012;

6 Wood et al., 2004).

7 Hydrologic planning is strongly dictated by the frequency and magnitude of sustained low or

8 high flow anomalies that affect water resources systems. The importance of these anomalies

9 becomes even greater when the system is stressed and water demand is close to the overall

10 availability in the system. Past assessments have evaluated such anomalies based on raw

11 GCM simulations. However, most water resources assessments at a catchment scale require some post-processing or bias correction, before any evaluation (for drought or for other purposes) can be carried out. This contradiction lays the foundation for this research; the key question that is posed is whether bias correction is needed for drought assessment at the scale of a catchment, a region, or an entire continent.

To this end, we assess drought simulations across Australia using monthly precipitation simulations from $22 \mathrm{GCMs}$ of the historical and future climate. We then repeat this assessment using the same GCMs, but after applying two established alternatives for bias correction. One of these alternatives, the Nested Bias Correction (NBC) (Johnson and Sharma, 2012) was designed specifically to correct low frequency variability bias in

21 simulations. The other method, Quantile Mapping (QM) corrects distributional attributes of 22 simulations instead of focusing on persistence related attributes. Our investigation uses these approaches to examine the differences that result with reference to a future climate. We then ask whether raw GCM simulations are indeed different from bias corrected simulations of 
1 drought, and if so whether there are clear advantages in using one of the two bias correction

2 alternatives evaluated.

3 The remainder of this paper is as follows. In Section 2 the bias correction methodologies and

4 the data sources used for the analysis are described. Section 3 discusses the drought and

5 rainfall statistics that have been considered. Section 4 applies the technique to $20^{\text {th }}$ century

6 rainfalls over Australia to compare the modeling of drought using observed, raw GCM

7 outputs and the bias correction techniques. In Section 5 comparisons of projected changes in

8 drought from the raw and bias-corrected GCM outputs are presented. The final section

9 discusses the implications of the results for future drought assessment and draws conclusions

10 that will be useful for water resources climate change impact assessment.

\section{2. Bias correction of GCM precipitation}

\section{2.1. Background}

13 Recent comparisons of bias correction methods (Gudmundsson et al., 2012; Johnson and

14 Sharma, 2011; Teutschbein and Seibert, 2012) have shown that the assumptions of the

15 correction method can affect their performance.Gudmundsson et al. (2012) found that nonparametric methods lead to the lowest errors, whilst Teutschbein and Seibert (2012) recommend power transformations or quantile mapping. Quantile mapping has been found in particular to be useful for correcting high rainfall totals of daily data (Themeß1 et al., 2012). If year to year variability in rainfall is an important driver of the behavior of a water resources system then it is necessary to consider biases in persistence as well as the distribution of the monthly rainfall data (Johnson and Sharma, 2011). The importance of this is highlighted by Rocheta et al. (2014) who have recently shown that the majority of GCMs 
1 in the Coupled Model Intercomparison Project 3 (CMIP3) underestimate interannual

2 variability.

3 In practical terms, the effects of interannual and interdecadal precipitation variability

4 manifest as periods of drought or abnormally wet conditions that can lead to flooding (Kiem

5 et al., 2003; Pui et al., 2011; Verdon et al., 2004). Therefore correctly modelling low-

6 frequency variability is the key to understanding possible changes to future water resources.

7 Future drought assessments have found that larger areas of land are expected to have

8 increased drought frequencies than decreases (Taylor et al., 2013) particularly for the later

9 parts of the $21^{\text {st }}$ century (Burke et al., 2006). Areas of the largest increases in drought

10 frequencies are the Amazon, Central America and South Africa (Dai, 2013; Taylor et al.,

11 2013) which is broadly consistent with the results from other studies (Burke and Brown,

12 2008; Orlowsky and Seneviratne, 2013) although the studies use different climate models and

13 emission scenarios. These projections are also consistent with observed trends of drought

14 frequency based on soil moisture anomalies (Orlowsky and Seneviratne, 2013).

15 A recent comprehensive study of global drought (Prudhomme et al., 2014) has been carried

16 out as part of the Inter-Sectoral Impact Model Intercomparison Project (Warszawski et al.,

17 2014). The analyses considered daily runoff and compared it to a daily drought threshold set

18 at the $10^{\text {th }}$ percentile of the daily values from the period 1976-2005. For large parts of the

19 world, large increases in drought frequency were found particularly in Australia. The use of

20 daily drought thresholds does not provide further guidance on longer term droughts due to

21 interseasonal or interannual variability.

22 One of the problems with previous assessments of future drought frequencies is that generally

23 they have not considered biases in the GCM precipitation simulations (e.g. Burke and Brown,

24 2008; Taylor et al., 2013). Wang and Chen (2014) used the Bias Correction and Spatial 
1 Disaggregation method of Wood et al. (2004) but did not assess the improvements in drought

2 representation in the current climate or the effects of bias correction on the future projections.

3 Prudhomme et al. (2014) also used bias corrected simulations and note that "statistical bias

4 correction can influence the signal of the runoff changes". They go on to state that this

5 uncertainty is believed to be smaller than the structural uncertainty associated with the choice

6 of GCM or global impact model. Our study addresses this assumption directly by considering

7 whether bias correcting GCM simulations improves the representation of historical drought

8 statistics and then secondly if the bias correction leads to differences in the projected

9 frequencies of future droughts. Changes at the individual grid cell are to be expected;

10 specifically we are interested in whether bias correction leads to different estimates of

11 drought at the regional or continental scales.

\section{$12 \quad$ 2.2. Bias correction methods}

13 Bias correction techniques have been developed to allow the direct use of GCM outputs for

14 climate change impact assessment applications, whilst accepting that there are problems in

15 the GCM modeling of rainfall (Johnson and Sharma, 2012). Bias correction approaches

16 previously proposed include monthly (Wood et al., 2004) or daily (Ines and Hansen, 2006),

17 quantile matching (Christensen et al., 2008; Gudmundsson et al., 2012) and simple monthly

18 correction factors (Fowler and Kilsby, 2007). One of the weaknesses of all these approaches

19 is that they only consider biases in the distribution of GCM simulations and not the

20 persistence of the simulations. Biases in the representation of persistence translate to a poor

21 characterization of interannual variability which can be particularly important when assessing

22 the impacts of climate change on water resources availability and infrastructure. The features

23 of interannual variability that are important include the sequencing of wet and dry years and

24 the standard deviations and correlations at time scales longer than a year. Because the focus 
1 of our work is on this interannual variability and annual and multi-year droughts, we focus on

2 monthly simulations from the GCMs.

3 Johnson and Sharma (2012) proposed the NBC method to correct the representation of

4 variability and persistence in the GCM outputs at multiple time scales. The approach was

5 developed based on the rationale in Koutsoyiannis (2001) which allows two time series of

6 different temporal resolutions to be combined, maintaining their individual stochastic

7 properties whilst ensuring that they are consistent with each other. Full details of the method

8 can be found in Johnson and Sharma (2012) with a summary of the main ideas presented

9 below.

10 The NBC method post-processing methodology is sufficiently general so that it can correct

11 distributional and persistence attributes on multiple time scales of interest. For the general

12 implementation of the nesting algorithm, the bias-corrected time series can be expressed as

13 shown in equations (1) to (3).

$16 \quad \tilde{P}_{i, j}^{m}=g_{i}\left(P_{i, j}^{m} \mid P_{i, j}^{h}, \theta_{i}\right)$

$17 \quad \tilde{P}_{j}^{\prime m}=\sum_{i} \tilde{P}_{i, j}^{m}$

$18 \quad \widetilde{P}_{j}^{m}=g_{j}\left(\widetilde{P}_{j}^{\prime m} \mid P_{j}^{h}, \theta_{j}\right)$

19 where $g_{()}$and $\theta_{()}$represent the transformation model and associated parameters for each of the

20 time scales of interest which are monthly $(i)$ and annual $(j)$ for the purposes of drought

21 assessment. $P^{m}$ is the modelled output at monthly or annual time scale (i.e. for the $i$ th month 
1 and $j$ th year or just the $j$ th year in the case of the annual sequence), $\tilde{P}^{\prime m}$ is the aggregated

2 partially corrected model output after one level of nesting and $\tilde{P}^{m}$ is the corrected output and

$3 P^{h}$ is the observations over the historical period. The aim is to transform the modeled outputs

4 such that $\widetilde{P}^{m}$ exhibits the same distributional and persistence attributes as $P^{h}$ across the

5 nesting time scales used. The parameters $\theta$ to be corrected are the mean, standard deviation

6 and lag-1 autocorrelation coefficient although in principle any statistics could be chosen

7 (Johnson and Sharma, 2012).

8 To achieve this, the corrections at the monthly level are first calculated for each month by

9 finding the mean, standard deviation and autocorrelation and applied to the model

10 simulations (Equation 1). These corrected simulations are then aggregated to the annual level

11 (Equation 2) and the next level of corrections is applied (Equation 3). The annual mean is

12 already corrected by the monthly mean correction but the annual variability and persistence

13 will not necessarily be correct until Equation 3 is applied. A further extension of NBC was

14 presented as the Recursive NBC (Mehrotra and Sharma, 2012) that repeats the nesting

15 process several times to further reduce the biases.

16 Quantile mapping has also been used to post-process the GCM outputs to assess drought

17 modelling for the historical and future climates. The idea behind quantile mapping is to use

18 either an empirical distribution or fitted probability distribution to match the observed and

19 modeled rainfall quantiles (Gudmundsson et al., 2012; Maurer et al., 2013; Teutschbein and

20 Seibert, 2012; Wood et al., 2004). Using similar notation as for NBC the quantile mapping is

21 described in Equation 3 where $q$ is the quantile of interest and $\mathrm{F}$ is the empirical cumulative

22 distribution function with $\mathrm{F}^{-1}$ its inverse.

$23 \quad \tilde{P}_{i, q}^{m}=F_{h}^{-1}\left(F_{m}\left(P_{i, q}^{m}\right)\right)$ 
1 In the implementation here, we use the empirical cumulative distribution for each month to

2 do the correction. The mapping can then be used for the future rainfall simulations. In

3 practice the rainfall amount for month $i$ and year $j$ from the GCM is ranked against all rainfall

4 totals for month $i$. The rainfall total with the same rank in the observed data is adopted as the

5 corrected amount. This lookup table can then be used for the future simulations by assuming

6 that the bias is multiplicative and that the ratio of the observed to modeled rainfall can be

7 applied to correct the future simulation.

8 The advantage of quantile mapping is that it can correct the full distribution of rainfall

9 amounts including the extreme wet and dry tails (Themeßl et al., 2012). Biases in the

10 skewness of the rainfall distribution are also addressed through this correction method. An

11 important disadvantage in the context of drought modelling is that the persistence in the

12 GCM time series (i.e. the relationship between adjacent months or years) cannot be

13 addressed. It is therefore of interest how the different bias correction methods behave for both

14 the current climate and the future simulations.

\section{$15 \quad$ 2.3. Data}

16 In this study, the two bias correction methods have been applied to the simulations of

17 precipitation from the Coupled Model Intercomparison Project (CMIP3) with the intention of assessing the impact they have on drought simulations for the future. GCM simulations at monthly time steps were used and all available ensemble members were corrected. All GCMs outputs were interpolated to a common T63 grid to allow the results to be compared across space. For the historical climate, the $20^{\text {th }}$ century simulations were used from 1900-1999 and

22 for the future simulations the SRESA2 scenario was adopted for a 30 year period at the end 23 of the $21^{\text {st }}$ century. To test the modelling of drought for the historical climate, a split sample approach was used with first half of the record used to calibrate the bias correction and the 
1 second half of the record used for an independent validation. Table 1 lists the GCMs that

2 have been used in the study.

3 Gridded monthly rainfall data over Australia from the Bureau of Meteorology (BOM) was 4 used as the observational data set (Grant et al., 2008). This product was created as part of the

5 Australia Water Availability Project (AWAP) from daily rainfall stations and Barnes

6 successive correction and three-dimensional smoothing splines to interpolate the rainfall onto

7 a 0.05 degree grid (Grant et al., 2008). Data already aggregated to monthly time series was

8 provided by the Bureau of Meteorology. Data from 1900 to 1999 was used for the analyses to

9 match the $20^{\text {th }}$ century simulations from the GCMs. Area averaging was used to re-grid the 10 data to the same resolution as the GCM outputs.

\section{3. Drought statistics}

12 There are a number of ways to assess the severity of drought and even the definition of

13 drought has a range of meanings. For this work meteorological drought has been considered

14 as the assessment is based on rainfall sequences. The timescales of interest are those more

15 generally considered with hydrological drought i.e. deficits in the order of a year to multiple

16 years or decades. In other parts of the world with less inherent climate variability drought

17 conditions can result from deficits as short as three to six months (Fowler et al., 2007b).

18 The SPI was developed to provide a simple calculation of drought (Guttman, 1999). An

19 incomplete gamma distribution is fitted to running totals of rainfall, and then transformed to a

20 standard normal distribution. The quantiles of the normal distribution are used to assess the

21 severity of the drought. Negative values of the index occur during dry periods, with positive

22 values indicating wet conditions. The SPI can be calculated for varying intervals; intervals of

231,2 and 5 years have been assessed in this study. The SPI has been used for future drought 
assessments by Burke and Brown (2008). Mpelasoka et al. (2008) note that because the SPI can be calculated on different time scales it can account for the effects of rainfall deficits of varying lengths on separate parts of the hydrologic cycle. As in the work by Burke and Brown (2008) a severe drought threshold has been set at the $5^{\text {th }}$ percentile of the SPI distribution at each location. Future changes can be assessed by counting the number of exceedances of this threshold. If the future is drier, then exceedances of the threshold will occur more frequently than in the historic climate (i.e. $5 \%$ of all time periods). The converse is also true for wetter future conditions. The spell length of the maximum deficit period in the SPI sequences has also been calculated.

A number of other statistics of rainfall that have been used for drought or water resources assessments have been considered to understand the ability of GCMs to represent interannual variability correctly and the impacts of bias correction on the current and future projections. The first rainfall statistic that has been considered is the coefficient of variation of multi-year rainfall sequences (2 year and 5 year specifically). A similar statistic (the minimum of running sums of 2 year and 5 year rainfall totals) was used by Srikanthan and Pegram (2009) to evaluate stochastically generated rainfall sequences. Johnson and Sharma (2011) found that the minima of the time series could be too noisy and instead adopted the standard deviation. The standard deviations are scaled by the annual mean to allow comparisons across space and are therefore equivalent to the coefficient of variation.

The rescaled range is calculated from a residual mass curve, which measures the cumulative departure of a time series from its mean. The difference between the maximum and minimum of the residual mass curve is the range, which can be scaled by the standard deviation of all deficits/surpluses. The rescaled range is used in water resources management as a surrogate of reservoir storage. It is a useful statistic for assessing GCM simulations of drought as 
1 storage calculations integrate dependence and trends that may be present in the time series

2 (Koutsoyiannis, 2002).

3 Figure 1 shows the annual rainfall time series and estimates of SPI and rescaled range for two

4 locations in Australia. The first location has higher rainfalls (shown in red in Figure 1a) but

5 lower multiyear variability. The second location is more arid with mean annual rainfall

6 (MAR) of the order of $300 \mathrm{~mm}$ but there is large year-to-year variability. This difference in

7 variability is evident when the annual rainfall time series are scaled by the MAR. The

8 majority of years at the high rainfall site are within $50 \%$ of the mean, whilst at the low

9 variability site, the annual distribution is much more skewed with a number of very dry years

10 and several very wet years with rainfalls more than double the MAR. Using multiple year

11 rainfall totals smooths the curves in Figure $1 \mathrm{~b}$ and emphasizes the persistence at the site with

12 high variability with a number of consecutive dry years or wet years. Next, the SPI values are

13 calculated for the two sites for 1 year and 5 year drought estimates. Interestingly the

14 difference between the two time series in terms of their multi-year persistence is not reflected

15 in the SPI series. This is because at each location the rainfall series are transformed via a

16 truncated gamma distribution to a normal distribution. Thus in all locations the range of

17 values is approximately between \pm 4 and therefore the SPI values cannot be used to

18 discriminate between sites with low or high interannual variability. This means that the SPI

19 is useful for comparing how future droughts might vary at one location but is not effective for

20 comparing drought severity at different locations.

21 Spells of dry months can be used to consider persistence and drought characteristics of time

22 series. The number of consecutive months when rainfall or streamflow is below some

23 threshold is called the "Run Length". Peel et al. (2005) propose a drought vulnerability

24 statistic by comparing run lengths of rainfall below the median. The run lengths can also be 
1 calculated for any other threshold of interest such as the mean or a value with a more frequent

2 exceedance probability. The cumulative sum of the deficits below the threshold is calculated

3 for every dry spell. The drought vulnerability is then defined as the maximum deficit below

4 the chosen threshold and it is standardized across space by dividing by the mean annual

5 rainfall. Readers interested in this concept are referred to Peel et al. (2005) for more

6 information on these statistics.

7 Counts of annual rainfall totals below the mean or median can also be constructed in other

8 ways. Ault et al. (2014) have assessed long-term sequences of flows by counting the number

9 of times that the flow/rainfall falls below 0.5 standard deviations from the mean. Depending

10 on the coefficient of variation of the data, this test can yield quite similar results to

11 considering rainfalls that are more than $75 \%$ below MAR (denoted as MAR75 in the

12 remainder of the paper). On the other hand when the coefficient of variation is small, then

13 there will be far few instances of rainfall less than $75 \%$ of the mean than when using the 0.5

14 standard deviation threshold. Figure 2 shows the relationship of the Peel drought

15 vulnerability with the two methods of counting rainfall below a threshold for the same two

16 locations as shown in Figure 1. For the site with high rainfall and relatively low variability

17 (red lines), the difference between using MAR75 threshold (Figure 2a) to the 0.5 standard

18 deviation is quite evident, whereas for the site with low variability the thresholds are quite

19 similar. The MAR75 statistic therefore appears to have better discrimination between sites

20 with high and low interannual variability than using the standard deviation measure of Ault et

21 al. (2014). In terms of drought vulnerability (Figure 2c), there is quite a large difference between the estimates at the two sites. The high variability site has large vulnerability due to the large deficit that occurs around 1960. All but one of the spells below the median last more

24 than one year at this location, compared to only 30\% (5 of 16) of the runs at the high rainfall, 25 low variability site. 
1 In Figure 3 the observation based estimates of each of the rainfall and drought statistics at all

2201 grid cells in Australia are compared. The statistics are calculated for the period from

3 1950-1999 and the SPI severe drought frequencies are calculated relative to the threshold

4 calculated for the earlier part of the record. This gives a sense of the performance that could

5 be expected from the GCMs and the bias correction methods if there were no biases. It can be

6 seen that there is high correlation between most of the statistics. The probability of annual

7 rainfall being more than 0.5 standard deviations below the mean is less well correlated with

8 the other rainfall statistics, in particular the Peel vulnerability and the rescaled range. As

9 discussed for Figure 1 there is less agreement between the SPI and other statistics due to the 10 standardization in the SPI calculations.

\section{4. Historical climate drought representation in GCMs}

13 Using the same statistics as the previous section, the ability of the CMIP3 GCMs to capture

14 the important features of rainfall persistence for water resources management is now assessed. The Root Mean Square Error (RMSE) has been calculated for each GCM by comparing drought statistics based on the raw or bias-corrected simulations to the observations for the period 1950-1999. The RMSE reflects the average error across all grid cells in the domain. In Figure 4 the RMSEs for six different drought statistics are shown for all of the first ensemble members from the $18 \mathrm{GCMs}$. Unsurprisingly in the majority of cases errors are much larger for the raw GCM simulations than either of the bias-corrected alternatives. For the first three rainfall-based statistics, the NBC method leads to smaller errors than the QM method for the majority of the GCMs. For the Peel drought vulnerability and the SPI statistics, the raw GCM simulations never have the smallest error and the QM is the preferred method in around $70 \%$ of the cases. This suggests that different drought 
1 statistics capture varying characteristics of the rainfall time series. In the case of the SPI and

2 drought vulnerability, it appears that biases in the rainfall distribution are more critical in

3 correctly representing the drought than biases in the persistence. As shown in Figure 1, the

4 rescaled range and multi-year rainfall totals are strongly affected by persistence and therefore

5 the NBC will perform better in correcting biases in their representation.

6 In Figure 5 the spatial patterns of errors across Australia are shown for the raw GCM

7 simulations and the bias-corrected outputs. In this case, error is defined at each grid cell as

8 the RMSE of the estimate from the 18 GCMs compared to the observation at that location.

9 The patterns of errors in the raw simulations are reasonably consistent for the three chosen

10 drought statistics (left column), with the largest errors in the center of the country and

11 relatively smaller errors in the southeast. Both bias correction methods substantially reduce

12 the errors. For the Peel drought vulnerability and MAR75 statistics, the pattern of errors after

13 bias correction broadly follows the raw simulations, with the smallest errors tending to occur

14 in the southeast and around the coast. For the SPI Severe Drought the patterns of errors are

15 relatively uniform after bias correction, particularly when compared to the other drought

16 statistics. The slight spatial variation in the errors shows that they are reversed after bias

17 correction with the smallest errors in the north and central parts of Australia and relatively

18 higher errors occurring in the southeast. As discussed earlier the SPI is standardized across

19 space so the impact of the magnitude of rainfall or the interannual variability at any particular

20 location is lessened. For all three drought statistics there is little difference in the performance

21 of the two bias correction methods when aggregated over all the models.

22 The results presented thus far have been aggregated across space or models. In Figure 6 and 7

23 results for two GCMs are shown to illustrate how the errors in raw and bias corrected GCM

24 vary at individual grid cells. In Figure 6, the results from CSIROMk3.5 are presented. In this 
1 GCM the NBC method consistently outperforms the QM results, due to the specific structure

2 of the biases in the GCM simulation. For this GCM it is found that the rainfall distributions

3 generally have a similar shape to the observed distributions and therefore corrections of the

4 first and second moment are sufficient without the need to correct the full distribution

5 (Johnson and Sharma, 2012). Under these circumstances the autocorrelation corrections are

6 effective and the NBC method improves the representation of persistence in the model and

7 therefore also the drought statistics.

8 In Figure 7, similar results are presented for INGV_ECHAM4 where it is clear that the raw

9 GCM simulations are much too wet with all drought statistics substantially underestimated.

10 For this GCM the QM method generally leads to smaller errors. The NBC overcorrects the

11 persistence leading to slightly larger drought estimates than the QM method although the results are much improved in both cases compared to the raw GCM simulations. For example in Figure 7d two grid cells have been labelled and it can be seen that in these locations the drought vulnerability is close to double the observed vulnerability using the NBC method whilst the QM method has matched the observations reasonably well. Reviewing the time series of monthly rainfall, the NBC method has produced more zero rainfall months than the observations and several multi-month spells of zero rainfall that are not seen at all in the observations. The QM has slightly fewer dry months than the observations but does not lead to any overly long dry spells and hence the vulnerability is represented better.

\section{5. Drought projections for 2080}

21 In the previous section, bias correction approaches were shown to improve the representation

22 of drought for the historical climate significantly compared to raw GCM simulations. Now it

23 is of interest how drought frequencies may change in the future. Previous studies have

24 considered future drought frequencies as changes relative to current climate drought 
1 thresholds (Burke and Brown, 2008). The important implication of this approach is that any

2 biases in the current climate simulations are firstly ignored and secondly assumed to remain

3 constant in the future. In this study, biases in the current climate are explicitly calculated and

4 assessed. However, as for any bias correction application the assumption that biases are

5 stationary in time is still required for the bias correction to be valid in the future (Maurer et

6 al., 2013; Teutschbein and Seibert, 2012). Haerter et al. (2011) showed that future changes

7 from bias corrected simulations can be different from those calculated using raw climate

8 model simulations and the differences depend on the assumptions of the bias correction

9 method. Here we further consider this point in the context of drought statistics and compare

10 the bias-corrected future drought frequencies to raw simulations from GCMs to identify the

11 effects of bias correction.

12 For each of the drought statistics presented in Section 4 the future drought frequencies

13 relative to the historical climate have been calculated. For the raw GCM simulations, the

14 historical climate case is the $20^{\text {th }}$ century GCM simulations without any corrections. The

15 bias-corrected future sequences are compared to the observed drought frequencies for 1970 to

161999 , acknowledging that the bias correction is not perfect so there will be some errors in this

17 comparison.

18 In Figure 8 the raw GCM future drought frequencies for each grid cell and each model are

19 compared to the future bias corrected drought frequencies. A local polynomial regression is

20 fitted to the data in each panel to explore the relationship between drought frequencies with

21 and without bias correction. Three drought statistics have been considered.

22 The first statistic presented in Figure 8 is the severe drought thresholds from the SPI as

23 defined by Burke and Brown (2008) (top row of Figure 8). When future conditions are drier

24 the historical severe $\left(5^{\text {th }}\right.$ percentile $)$ drought threshold will be exceeded more frequently. For 
1 example, a future drought frequency of $20 \%$ means that the event that currently only occurs

2 with a return period of 1 in 20 will occur in the future with a return period of 1 in 5 . Such

3 conditions are evident in Figure 8 where approximately $50 \%$ of grid cells and models project

4 drier conditions and the frequency of exceeding the current drought thresholds increases.

5 These large changes tend to be found in the southern parts of the country and are evident

6 whether raw or bias corrected simulations are used.

7 When the raw GCM estimates are compared to the bias-corrected estimates, it can be seen

8 that the fitted regression line lies below the one to one line at the highest frequencies. This

9 means that bias correction tends to lead to smaller future increases in drought frequency than

10 using raw GCM simulations. For both bias correction approaches the threshold for this

11 moderation starts at raw drought frequencies of around $30 \%$. This response is consistent for

12 both the moderate and severe drought thresholds and for both bias correction approaches.

13 Similar results are found when the Peel drought vulnerability and MAR75 statistic are

14 considered (middle and bottom rows of Figure 8). For these cases, the future drought

15 estimates are calculated by using the median or mean annual rainfall from historical climate

16 with the future climate time series. For example the MAR75 future drought statistic

17 calculates the percentage of years in the future where the rainfall falls below $75 \%$ of the

18 1970-1999 mean annual rainfall. Even in the historical climate the value of this statistic will

19 vary depending on the variance and skewness of the annual rainfall time series and therefore

20 it is not obvious from Figure 8 which estimates are wetter or drier than the historical climate

21 except for the SPI statistic. This is the clear advantage of using the predefined thresholds of

22 the SPI, which by definition are known drought frequencies. The disadvantage of the

23 threshold exceedances is that they give no measure of the relative wetness or dryness of

24 different locations unlike the MAR75 and Peel drought vulnerability. 
1 How do drought frequencies change at individual locations and is there a strong spatial

2 pattern to these changes? Figure 9 provides the consensus position from all the GCMs for raw

3 and bias-corrected changes in drought frequency. In the top row, the drought frequency using

4 the SPI 5 year severe drought threshold is assessed, whilst the bottom row shows the results

5 using the Peel drought vulnerability. Increased (decreased) drought frequency is shown in red

6 (blue) when two-thirds of the GCMs project drier (wetter) conditions. The areas shown in

7 grey occur when the GCMs are more evenly split in whether wetter or drier conditions will

8 occur in the future. In the case of the SPI there are two clear signals whether raw or bias

9 corrected results are used. Wetter conditions are projected for northern Australia and drier

10 conditions in the south, particularly in southwestern Western Australia and along the eastern

11 coast of the Great Australian Bight. Interestingly in the southeast less frequent droughts are

12 projected if bias-corrected simulations are used whereas the raw GCMs show mixed signals.

13 After bias correction at these locations a small number of GCMs (around 2 to 5 models) have

14 lower drought frequencies than found in the raw simulations and this is enough to then cross

15 the threshold of two-thirds of models agreeing on the direction of the change. It is not always

16 the same GCM at each grid cell where the drought frequencies change direction.

17 There is considerable uncertainty in the projections of the future drought frequency that is

18 masked by the use of mean changes or GCM consensus results. At each grid cell the

19 minimum and maximum future drought frequencies are found for all 38 model realizations

20 for the 5 year SPI severe drought threshold. The model spread is the difference between the

21 maximum and minimum values. In Figure 10, empirical cumulative distribution functions are

22 shown for the raw and bias-corrected model spread. These distributions represent the model

23 spread at the 201 grid cells. At approximately $10-15 \%$ of grid cells the model spread is $100 \%$

24 (the maximum possible) and bias correction does not improve this situation. The NBC

25 method decreases the range of all the remaining grid cells, implying a decrease in model 
1 structural uncertainty following bias correction. The QM method leads to an increase in

2 model spread at about $30 \%$ of grid cells but for the remainder of locations the range is

3 substantially decreased compared to the raw simulations. Decreases in uncertainty are found

4 mainly in the northern parts of Australia. Areas with the highest uncertainty are in the

5 southeastern part of the country and this is where uncertainty is not improved after bias-

6 correction.

\section{6. Discussion and conclusions}

8 In this paper we have sought to consider the impact of bias correction of GCM precipitation

9 simulations on future drought frequencies. We find that future drought frequencies for

10 Australia are expected to increase but bias correction tends to moderate these increases and in

11 some instances improves the consensus amongst a large set of GCMs.

12 One of the limitations of the study is that the drought assessments were only based on

13 precipitation simulations rather than drought measures that consider the full water balance.

14 Different drought projections would be expected if a combined drought index such as the

15 Palmer Drought Severity Index (PDSI) (Palmer, 1965) or the Reconnaissance Drought Index

16 (RDI) (Zarch et al., 2014) was used. Both of these approaches would require joint bias

17 correction of precipitation and potential evaporation (Piani and Haerter, 2012). This joint

18 correction is simple to formulate within the NBC framework, and amounts to the use of a

19 Multivariate Autoregressive Model instead of a simple Autoregressive Model in the bias

20 correction method (Mehrotra and Sharma, 2015). It is important to jointly correct the

21 temperature/evaporation and precipitation rather than implementing independent corrections

22 so that the dynamic relationships between the two can be maintained. 
1 An alternative to the joint modelling of precipitation and evaporation for drought is to assess

2 drought through analysis of soil moisture derived from the GCMs directly (Sheffield and

3 Wood, 2008). The disadvantage of this approach is that soil moisture is available for fewer

4 models than precipitation. There are also problems with attempting to bias correct soil

5 moisture projections from GCMs due to the sparse coverage of soil moisture observation

6 networks and additional problems with the scale discrepancy between the point

7 measurements and the GCM grids. Future work could investigate the utility of satellite soil

8 moisture products for this purpose.

9 Correctly understanding drought likelihood can allow society to prepare and manage water

10 resources systems to minimize the impacts of these devastating events. How drought

11 frequencies may change in the future due to anthropogenic climate change is a question of

12 interest to many sections. Answering this question is difficult due to the uncertainties in

13 climate model projections of rainfall in particular. Most previous drought assessments have

14 focused on the change in drought frequencies without explicitly considering the biases in the

15 rainfall and therefore in the drought estimates for the current climate. In this paper it is shown

16 that bias correcting precipitation simulations prior to calculating drought changes can lead to

17 different conclusions on future drought frequencies. A number of drought statistics were

18 considered including the Standardized Precipitation Index, statistics of the rainfall time series

19 on annual and inter-annual timescales and a drought vulnerability statistic. Two different bias

20 correction techniques were investigated that corrected the monthly GCM rainfall simulations,

21 namely Nested Bias Correction and Quantile Mapping. Both were shown to reduce the

22 prediction errors when the simulations are compared to drought frequencies calculated from

23 observed data. 
1 Future drought frequencies were assessed firstly using firstly raw GCM outputs, which

2 assumes that the biases in the GCMs are additive and can therefore be removed by taking

3 differences between the future and current projections. The bias corrected GCM outputs

4 using Quantile Mapping and Nested Bias Correction were also assessed. It was found for the

5 CMIP3 GCMs assessed in this study that bias correction tended to moderate the largest future

6 increases in drought frequency suggested when using the raw GCM outputs. It is thus

7 concluded that raw model simulations can lead to incorrect drought assessments even at

8 continental scales and bias corrections need to be applied. These results are consistent across

9 models and across the continent. A slight improvement in the agreement in the number of

10 models projecting drier or wetter conditions was also found after bias correction, although for

11 many parts of Australia there is still substantial uncertainty across the projections.

Acknowledgments

13 We acknowledge the modeling groups, the Program for Climate Model Diagnosis and Intercomparison (PCMDI) and the WCRP's Working Group on Coupled Modeling (WGCM) for their roles in making available the WCRP CMIP3 multi-model dataset. Support of this dataset is provided by the Office of Science, U.S. Department of Energy. We acknowledge the Australian Research Council and the Sydney Catchment Authority for partial funding to support this work.

\section{References}

Alley, W.M., 1984. The Palmer Drought Severity Index: Limitations and Assumptions. Journal of Climate and Applied Meteorology, 23: 1100-1109.

Ault, T.R., Cole, J.E., Overpeck, J.T., Pederson, G.T., Meko, D.M., 2014. Assessing the risk of persistent drought using climate model simulations and paleoclimate data. Journal of Climate.

Burke, E.J., Brown, S.J., 2008. Evaluating uncertainties in the projection of future drought. Journal of Hydromet., 9(2): 292-299. 
Burke, E.J., Brown, S.J., Christidis, N., 2006. Modeling the recent evolution of global drought and projections for the twenty-first century with the Hadley Centre climate model. Journal of Hydromet., 7(5): 1113-1125.

Buser, C., Künsch, H., Lüthi, D., Wild, M., Schär, C., 2009. Bayesian multi-model projection of climate: bias assumptions and interannual variability. Climate Dynamics, 33(6): 849-868.

Chan, S. et al., 2013. Does increasing the spatial resolution of a regional climate model improve the simulated daily precipitation? Climate Dynamics, 41(5-6): 1475-1495.

Chen, J., Brissette, F.P., Chaumont, D., Braun, M., 2013. Finding appropriate bias correction methods in downscaling precipitation for hydrologic impact studies over North America. Water Resources Research, 49(7): 4187-4205.

Christensen, J.H., Boberg, F., Christensen, O.B., Lucas-Picher, P., 2008. On the need for bias correction of regional climate change projections of temperature and precipitation. Geophys. Res. Lett., 35.

Dai, A., 2013. Increasing drought under global warming in observations and models. Nature Clim. Change, 3(1): 52-58.

Fowler, H.J., Blenkinsop, S., Tebaldi, C., 2007a. Linking climate change modelling to impact studies: recent advances in downscaling techniques for hydrological modelling. International Journal of Climatology, 27(12): 1547-1578.

Fowler, H.J., Kilsby, C.G., 2007. Using regional climate model data to simulate historical and future river flows in northwest England. Climatic Change, 80(3): 337-367.

Fowler, H.J., Kilsby, C.G., Stunell, J., 2007b. Modelling the impacts of projected future climate change on water resources in north-west England. Hydrology and Earth System Sciences, 11(3): 1115-1124.

Grant, I., Jones, D., Wang, W., Fawcett, R., Barratt, D., 2008. Meteorological and remotely sensed datasets for hydrological modelling: A contribution to the Australian Water Availability Project, Catchment-scale Hydrological Modelling \& Data Assimilation (CAHMDA-3) International Workshop on Hydrological Prediction: Modelling, Observation and Data Assimilation, Melbourne. Citeseer.

Gudmundsson, L., Bremnes, J.B., Haugen, J.E., Engen-Skaugen, T., 2012. Technical Note: Downscaling RCM precipitation to the station scale using statistical transformations a comparison of methods. Hydrology and Earth System Sciences, 16(9): 3383-3390.

Guttman, N.B., 1999. Accepting the standardized precipitation index: A calculation algorithm. Journal of the American Water Resources Association, 35(2): 311-322.

Haerter, J., Hagemann, S., Moseley, C., Piani, C., 2011. Climate model bias correction and the role of timescales. Hydrology and Earth System Sciences, 15(3): 1065-1079.

Ines, A.V.M., Hansen, J.W., 2006. Bias correction of daily GCM rainfall for crop simulation studies. Agricultural and Forest Meteorology, 138(1-4): 44-53.

IPCC, 2013. Climate Change 2013: The Physical Science Basis. Contribution of Working Group I to the Fifth Assessment Report of the Intergovernmental Panel on Climate Change. Cambridge University Press, Cambridge, United Kingdom and New York, NY, USA, 1535 pp.

Jiménez Cisneros, B.E. et al., 2014. Freshwater resources. In: Field, C.B. et al. (Eds.), Climate Change 2014: Impacts, Adaptation, and Vulnerability. Part A: Global and Sectoral Aspects. Contribution of Working Group II to the Fifth Assessment Report of the Intergovernmental Panel of Climate Change. Cambridge University Press, Cambridge, United Kingdom and New York, NY, USA, pp. 229-269.

Johnson, F., Sharma, A., 2010. A comparison of Australian open water body evaporation trends for current and future climates estimated from Class A evaporation pans and general circulation models. Journal of Hydromet., 11(1): 105-121. 
Johnson, F., Sharma, A., 2011. Accounting for interannual variability: A comparison of options for water resources climate change impact assessments. Water Resources Research, 47(4): W04508.

Johnson, F., Sharma, A., 2012. A nesting model for bias correction of variability at multiple times scales in general circulation model precipitation simulations. Water Resources Research, 48: W01504.

Kiem, A.S., Franks, S.W., Kuczera, G., 2003. Muti-decadal variability of flood risk. Geophysical Research Letters, 30(2): 1035.

Koutsoyiannis, D., 2001. Coupling stochastic models of different timescales. Water Resources Research, 37(2): 379-391.

Koutsoyiannis, D., 2002. The Hurst phenomenon and fractional Gaussian noise made easy. Hydrological Sciences Journal-Journal Des Sciences Hydrologiques, 47(4): 573-595.

Li, H., Sheffield, J., Wood, E.F., 2010. Bias correction of monthly precipitation and temperature fields from Intergovernmental Panel on Climate Change AR4 models using equidistant quantile matching. Journal of Geophysical Research, 115: D10101.

Maraun, D. et al., 2010. Precipitation downscaling under climate change: recent developments to bridge the gap between dynamical models and the end user. Reviews of Geophysics, 48(RG3003): 34.

Maurer, E.P., Das, T., Cayan, D.R., 2013. Errors in climate model daily precipitation and temperature output: time invariance and implications for bias correction. Hydrology and Earth System Sciences, 17(6): 2147-2159.

Mehrotra, R., Sharma, A., 2012. An improved standardization procedure to remove systematic low frequency variability biases in GCM simulations. Water Resources Research, 48(12).

Mehrotra, R., Sharma, A., 2015. Correcting for systematic biases in multiple raw GCM variables across a range of timescales. Journal of Hydrology, 520: 214-223.

Mpelasoka, F., Hennessy, K., Jones, R., Bates, B., 2008. Comparison of suitable drought indices for climate change impacts assessment over Australia towards resource management. International Journal of Climatology, 28(10): 1283-1292.

Orlowsky, B., Seneviratne, S.I., 2013. Elusive drought: uncertainty in observed trends and short- and long-term CMIP5 projections. Hydrol. Earth Syst. Sci., 17(5): 1765-1781.

Palmer, W.C., 1965. Meteorological Drought. Research Paper No.45.

Peel, M.C., McMahon, T.A., Pegram, G.G., 2005. Global analysis of runs of annual precipitation and runoff equal to or below the median: run magnitude and severity. International Journal of Climatology, 25(5): 549-568.

Piani, C., Haerter, J., Coppola, E., 2010. Statistical bias correction for daily precipitation in regional climate models over Europe. Theoretical and Applied Climatology, 99(1): 187-192.

Piani, C., Haerter, J.O., 2012. Two dimensional bias correction of temperature and precipitation copulas in climate models. Geophys. Res. Lett., 39(20): L20401.

Pitman, A.J., Arneth, A., Ganzeveld, L., 2012. Regionalizing global climate models. International Journal of Climatology, 32(3): 321-337.

Prudhomme, C. et al., 2014. Hydrological droughts in the 21 st century, hotspots and uncertainties from a global multimodel ensemble experiment. Proceedings of the National Academy of Sciences, 111(9): 3262-3267.

Pui, A., Lall, A., Sharma, A., 2011. How does the Inter-decadal Pacific Oscillation affect Design Floods in Australia? Water Resources Research, 47: W05554.

Rocheta, E., Sugiyanto, M., Johnson, F., Evans, J., Sharma, A., 2014. How well do general circulation models represent low-frequency rainfall variability? Water Resources Research, 50(3): 2108-2123. 
Sheffield, J., Wood, E.F., 2008. Global trends and variability in soil moisture and drought characteristics, 1950-2000, from observation-driven Simulations of the terrestrial hydrologic cycle. Journal of Climate, 21(3): 432-458.

Srikanthan, R., Pegram, G.G.S., 2009. A Nested Multisite Daily Rainfall Stochastic Generation Model. Journal of Hydrology, 371(1): 142-153.

Taylor, I. et al., 2013. The impact of climate mitigation on projections of future drought. Hydrology and Earth System Sciences, 17: 2339-2358.

Teutschbein, C., Seibert, J., 2012. Bias correction of regional climate model simulations for hydrological climate-change impact studies: Review and evaluation of different methods. Journal of Hydrology, 456: 12-29.

Themeß1, M.J., Gobiet, A., Heinrich, G., 2012. Empirical-statistical downscaling and error correction of regional climate models and its impact on the climate change signal. Climatic Change, 112(2): 449-468.

Verdon, D.C., Wyatt, A.M., Kiem, A.S., Franks, S.W., 2004. Multidecadal variability of rainfall and streamflow: Eastern Australia. Water Resources Research, 40(W10201).

Vörösmarty, C.J. et al., 2010. Global threats to human water security and river biodiversity. Nature, 467(7315): 555-561.

Wang, L., Chen, W., 2014. A CMIP5 multimodel projection of future temperature, precipitation, and climatological drought in China. International Journal of Climatology, 34(6): 2059-2078.

Warszawski, L. et al., 2014. The Inter-Sectoral Impact Model Intercomparison Project (ISIMIP): Project framework. Proceedings of the National Academy of Sciences, 111(9): 3228-3232.

Wells, N., Goddard, S., Hayes, M.J., 2004. A self-calibrating Palmer Drought Severity Index. Journal of Climate, 17(12): 2335-2351.

Wilcke, R.A.I., Mendlik, T., Gobiet, A., 2013. Multi-variable error correction of regional climate models. Climatic Change, 120(4): 871-887.

Wood, A.W., Leung, L.R., Sridhar, V., Lettenmaier, D.P., 2004. Hydrologic implications of dynamical and statistical approaches to downscaling climate model outputs. Climatic Change, 62(1-3): 189-216.

Zarch, M.A.A., Sivakumar, B., Sharma, A., 2014. Droughts in a warming climate: A global assessment of Standardised precipitation index (SPI) and Reconnaissance drought index (RDI). Journal of Hydrology, in press. 


\section{$1 \quad$ Figures and Tables}

2 Table 1: Details of GCMs used

\begin{tabular}{|c|c|c|c|}
\hline Modeling Group & Name & $\begin{array}{l}\text { Available } \\
\text { Ensembles }\end{array}$ & $\begin{array}{l}\text { Atmosphere } \\
\text { Resolution }\end{array}$ \\
\hline Bjerknes Centre for Climate Research, Norway & bccr_bcm2_0 & 1 & T63 $\left(\sim 1.9^{\circ}\right)$ \\
\hline $\begin{array}{l}\text { Canadian Centre for Climate Modelling and Analysis, } \\
\text { Canada }\end{array}$ & cccma_cgcm3_1 & 5 & T47 $\left(\sim 2.8^{\circ}\right)$ \\
\hline $\begin{array}{l}\text { Météo-France/Centre National de Recherches } \\
\text { Météorologiques, France }\end{array}$ & cnrm_cm3 & 1 & T63 $\left(\sim 1.9^{\circ}\right)$ \\
\hline $\begin{array}{l}\text { Commonwealth Scientific and Industrial Research } \\
\text { Organisation (CSIRO) Atmospheric Research, Australia }\end{array}$ & csiro_mk3_5 & 1 & T63 $\left(\sim 1.9^{\circ}\right)$ \\
\hline $\begin{array}{l}\text { U.S. Department of Commerce/National Oceanic and } \\
\text { Atmospheric Administration (NOAA)/ Geophysical Fluid } \\
\text { Dynamics Laboratory (GFDL), USA }\end{array}$ & gfdl_cm2_0 & 1 & $2^{\circ} \times 2.5^{\circ}$ \\
\hline $\begin{array}{l}\text { U.S. Department of Commerce/National Oceanic and } \\
\text { Atmospheric Administration (NOAA)/ Geophysical Fluid } \\
\text { Dynamics Laboratory (GFDL), USA }\end{array}$ & gfdl_cm2_1 & 1 & $2^{\circ} \times 2.5^{\circ}$ \\
\hline NASA/GISS, USA & giss_model_e_r & 1 & $4^{\circ} \times 5^{\circ}$ \\
\hline $\begin{array}{l}\text { INGV, National Institute of Geophysics and Volcanology, } \\
\text { Italy }\end{array}$ & ingv_echam4 & 1 & $\mathrm{~T} 106\left(\sim 1.125^{\circ}\right)$ \\
\hline Institute for Numerical Mathematics, Russia & inmcm3_0 & 1 & $4^{\circ} \times 5^{\circ}$ \\
\hline Institut Pierre Simon Laplace, France & ipsl_cm4 & 1 & $2.5^{\circ} \times 3.75^{\circ}$ \\
\hline $\begin{array}{l}\text { Center for Climate System Research (University of Tokyo), } \\
\text { National Institute for Environmental Studies and Frontier } \\
\text { Research Center for Global Change (JAMSTEC), Japan }\end{array}$ & miroc3_2_medres & 3 & $\mathrm{~T} 42\left(\sim 2.8^{\circ}\right)$ \\
\hline $\begin{array}{l}\text { Meteorological Institute of the University of Bonn, } \\
\text { Meteorological Research Institute of the Korea } \\
\text { Meteorological Administration (KMA), and Model and Data } \\
\text { Group, Germany/Korea }\end{array}$ & miub_echo_g & 3 & $\mathrm{~T} 30\left(\sim 3.9^{\circ}\right)$ \\
\hline Max Planck Institute for Meteorology, Germany & mpi_echam5 & 3 & T63 $\left(\sim 1.9^{\circ}\right)$ \\
\hline Meteorological Research Institute, Japan & mri_cgcm2_3_2a & 5 & T85 $\left(\sim 1.4^{\circ}\right)$ \\
\hline National Center for Atmospheric Research, USA & ncar_ccsm3_0 & 4 & T85 $\left(\sim 1.4^{\circ}\right)$ \\
\hline National Center for Atmospheric Research, USA & ncar_pcm1 & 4 & T42 $\left(\sim 2.8^{\circ}\right)$ \\
\hline $\begin{array}{l}\text { Hadley Centre for Climate Prediction and Research/Met } \\
\text { Office, UK }\end{array}$ & ukmo_hadcm3 & 1 & $2.5^{\circ} \times 3.75^{\circ}$ \\
\hline $\begin{array}{l}\text { Hadley Centre for Climate Prediction and Research/Met } \\
\text { Office, UK }\end{array}$ & ukmo_hadgem1 & 1 & $1.3^{\circ} \times 1.9^{\circ}$ \\
\hline
\end{tabular}




\section{Figures List}

2 Figure 1: Time series of annual rainfall and drought estimates for two locations in Australia

3 showing high interannual variability (black) and low interannual variability (red) a) shows the

4 annual rainfall time series, b) the annual rainfall scaled by MAR, c) the running sum of 5 year

5 rainfalls scaled by MAR, d) 1 year SPI time series, e) 5 year SPI time series and f) the

6 residual mass curve of running sums minus demand. Demand is defined to be equal to the

7 mean monthly rainfall.

8 Figure 2: As for the locations in Figure 1, time series of annual rainfall showing the

9 calculation of MAR75, estimates that are more than 0.5 standard deviations below the mean,

10 and Peel drought vulnerability.

12 Figure 3: Relationships between observed drought statistics. Each plot contains 201

13 estimates, representing the range of drought values across Australia.

14 Figure 4: Errors for each GCM in drought estimates, averaged over space for a) 5 year

15 rainfall time series standard deviation, b) rescaled range, c) MAR75, d) drought vulnerability,

16 e) SPI 5 year spell length and f) SPI 5 year severe drought threshold. The method that leads

17 to the smallest RMSE from the raw, NBC and QM results for each GCM has been used to

18 pick the line type.

19 Figure 5: Error in drought estimates at each grid cell calculated as the average across all 18

20 GCMs of RMSE between the observations and the GCM estimates for MAR75 (top row),

21 drought vulnerability (middle row) and for 5 year SPI Severe Drought frequency (bottom

22 row). Raw and bias corrected results are shown as the columns. The smallest errors are in red

23 colors whilst larger errors are shown in lighter colors. 
1 Figure 6: Comparison of observed and modelled drought statistics for the CSIRO Mk3.5

2 GCM for a) 5 year rainfall time series standard deviation, b) rescaled range, c) MAR75, d)

3 drought vulnerability, e) SPI 5 year spell length and f) SPI 5 year severe drought threshold.

4 Raw GCM simulations are shown in black, NBC in red and QM in blue. The RMSE of the

5 model estimates is shown in each panel.

$6 \quad$ Figure 7: As for Figure 6 but showing results for INGV_ECHAM4

7 Figure 8: Comparisons of raw and bias corrected projections of future drought for all grid

8 cells and all GCMs for 5 year SPI Severe Drought frequency (top row), drought vulnerability

9 (middle row) and MAR75 (bottom row). A local polynomial regression has been fitted in

10 each case to summarize the relationship between raw and bias-corrected estimates.

11 Figure 9: Spatial variation of model consensus in future changes in drought frequency for SPI

125 year severe drought (top row) and drought vulnerability (bottom row) for raw, NBC and

13 QM simulations. Areas shown in red (blue) have at least two-thirds of models projecting

14 increased (decreased) drought frequency in the future. Areas shown in grey have limited

15 model consensus on the direction of change in future droughts.

16 Figure 10: Empirical cumulative frequency distributions of the model spread across all GCMs

17 of the future drought frequency (5 year SPI) for raw and bias corrected simulations.

18 Uncertainty in the model projections is smaller when the spread is smaller. 

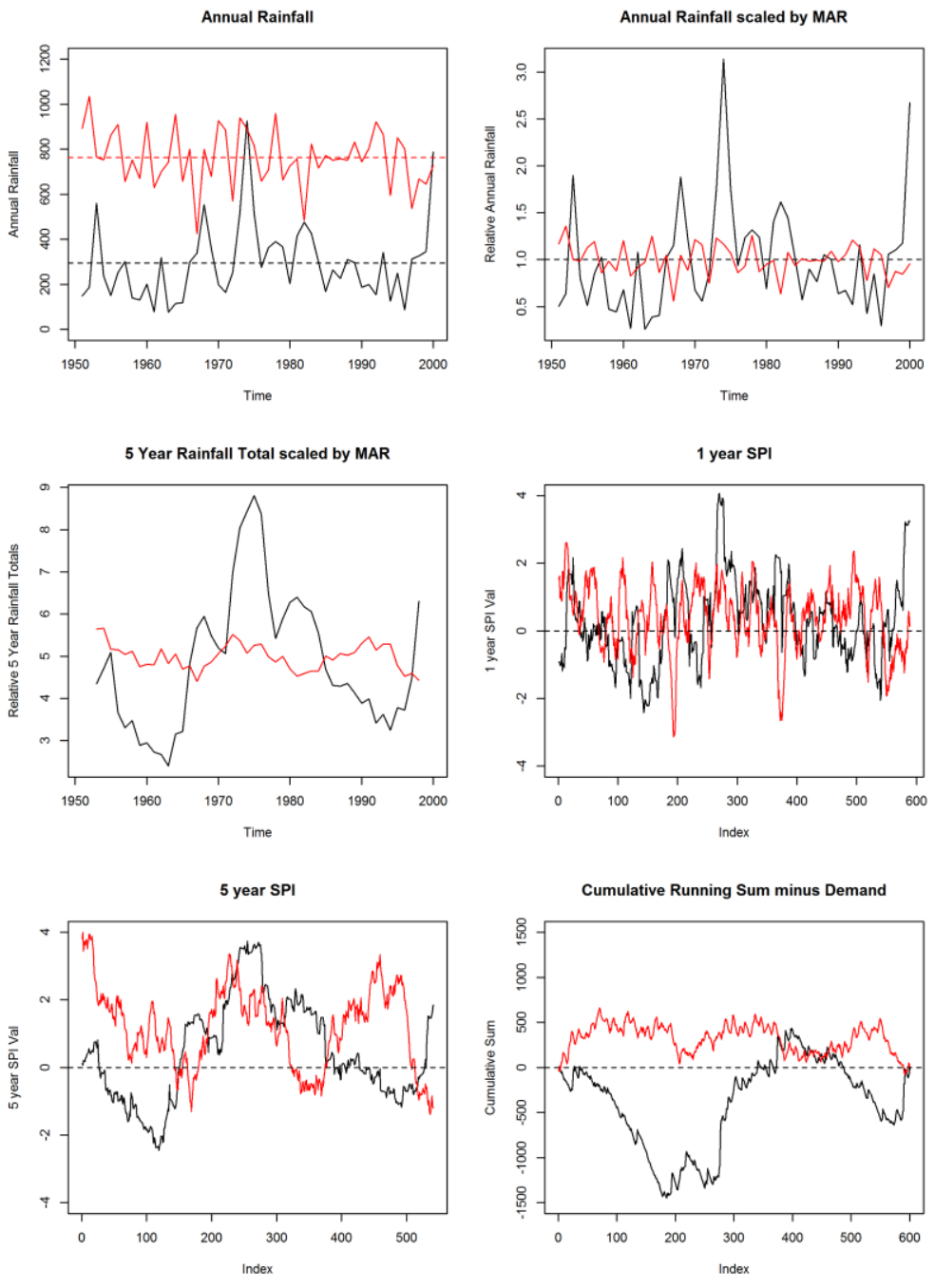

2 Figure 1:Time series of annual rainfall and drought estimates for two locations in Australia

3 showing high interannual variability (black) and low interannual variability (red) a) shows the 4 annual rainfall time series, b) the annual rainfall scaled by MAR, c) the running sum of 5 year

5 rainfalls scaled by MAR, d) 1 year SPI time series, e) 5 year SPI time series and f) the

6 residual mass curve of running sums minus demand. Demand is defined to be equal to the

7 mean monthly rainfall. 

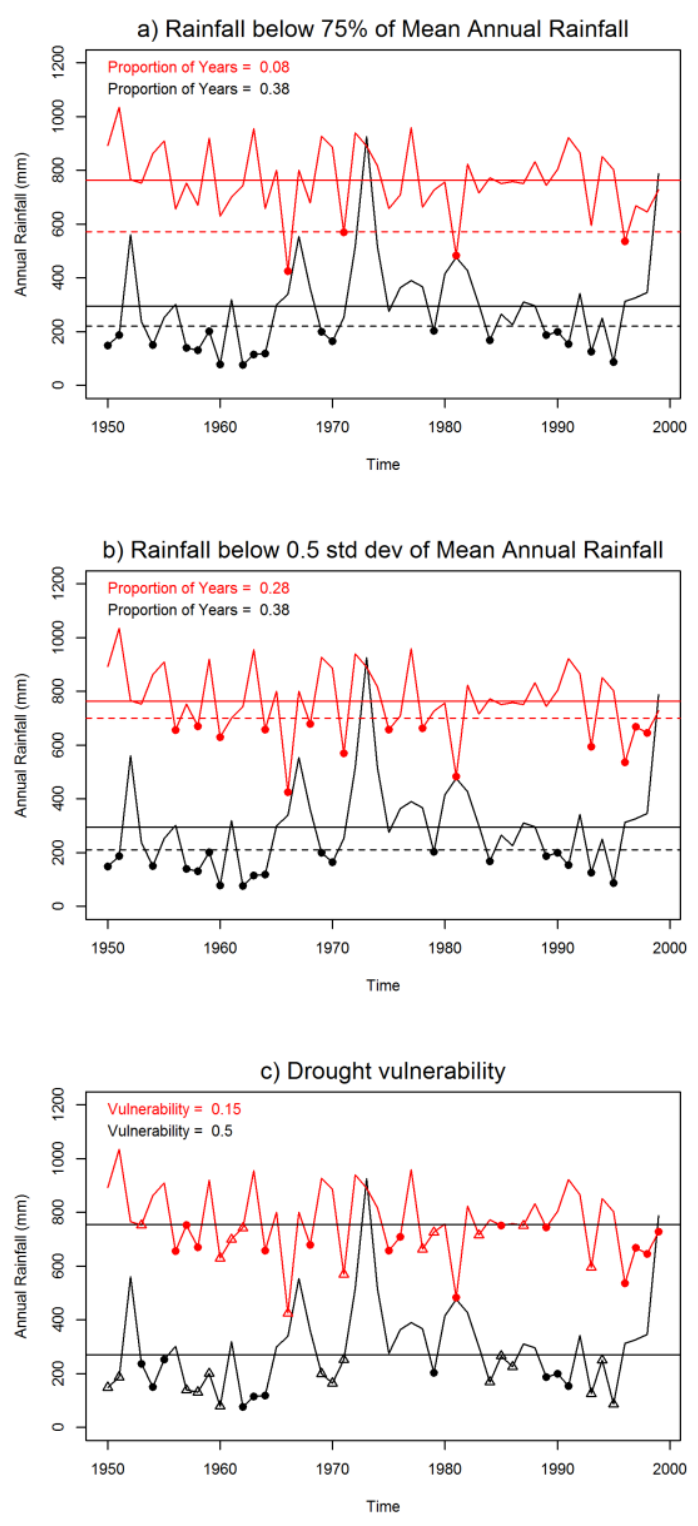

1

2 Figure 2: As for the locations in Figure 1, time series of annual rainfall showing the

3 calculation of MAR75, estimates that are more than 0.5 standard deviations below the mean,

4 and Peel drought vulnerability. 


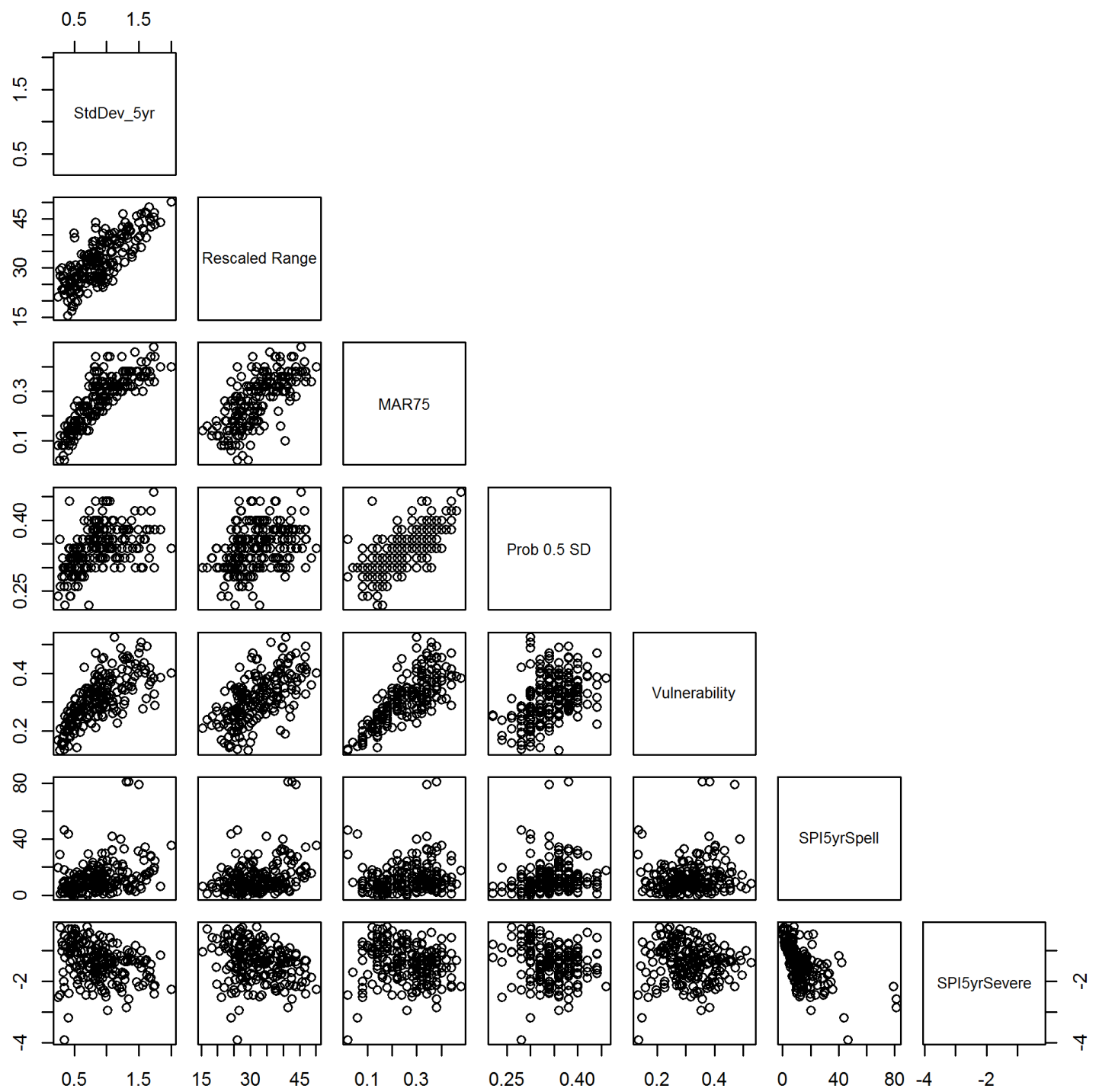

2 Figure 3: Relationships between observed drought statistics. Each plot contains 201

3 estimates, representing the range of drought values across Australia. 

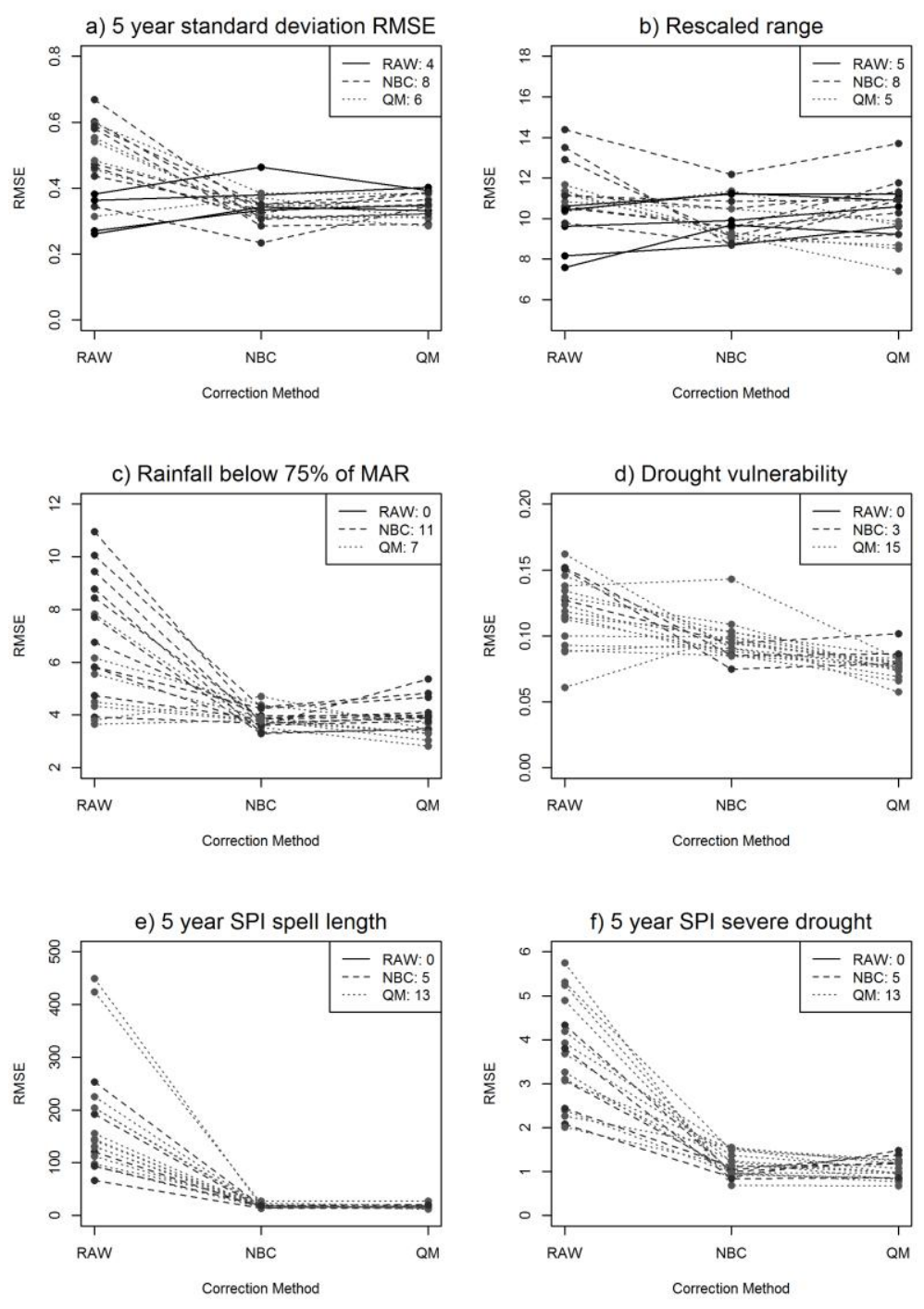

2 Figure 4:Errors for each GCM in drought estimates, averaged over space for a) 5 year rainfall

3 time series standard deviation, b) rescaled range, c) MAR75, d) drought vulnerability, e) SPI

45 year spell length and f) SPI 5 year severe drought threshold. The method that leads to the

5 smallest RMSE from the raw, NBC and QM results for each GCM has been used to pick the 6 line type. 

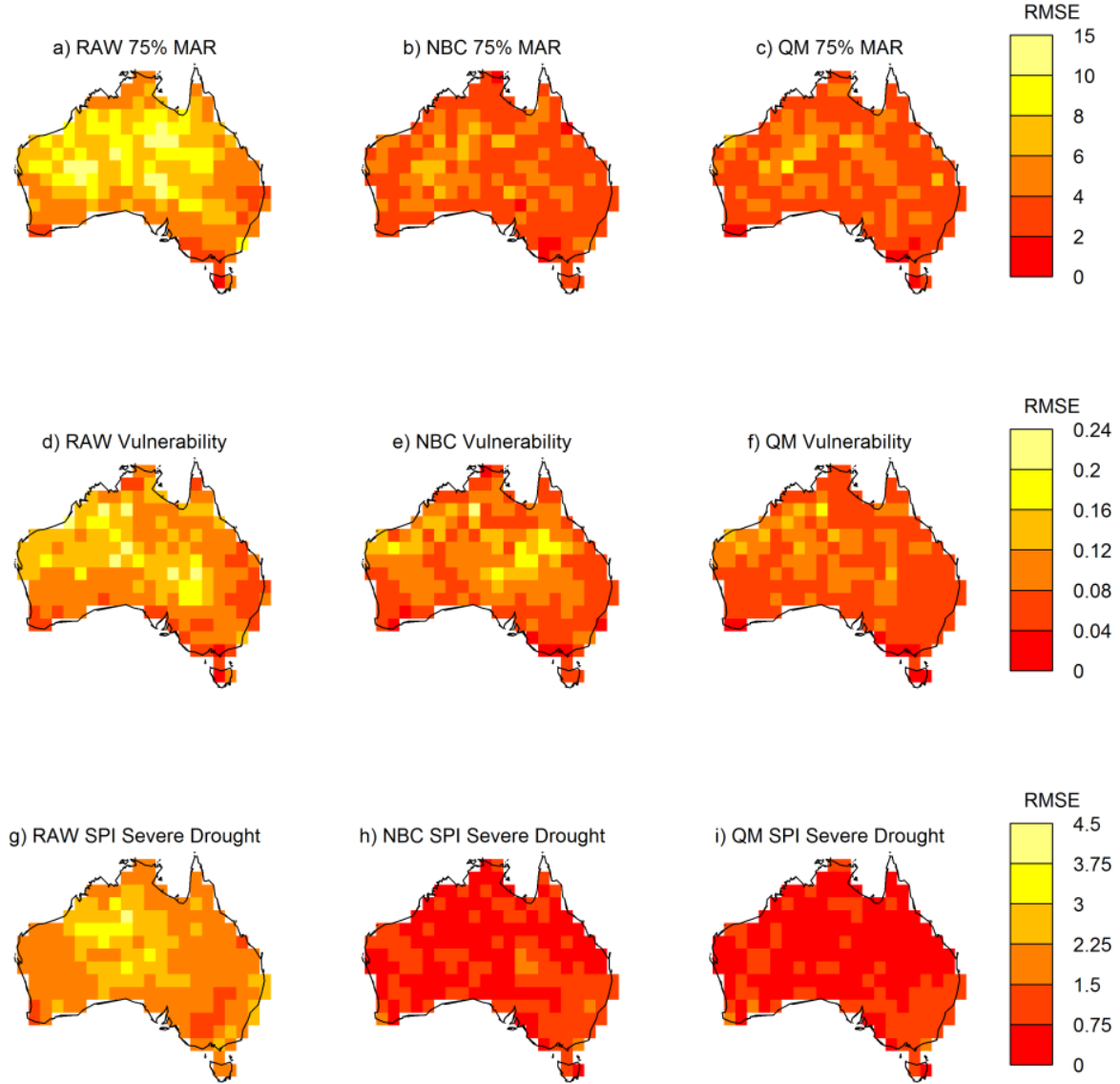

2 Figure 5: Error in drought estimates at each grid cell calculated as the average across all 18

3 GCMs of RMSE between the observations and the GCM estimates for MAR75 (top row),

4 drought vulnerability (middle row) and for 5 year SPI Severe Drought frequency (bottom

5 row). Raw and bias corrected results are shown as the columns. The smallest errors are in red

6 colors whilst larger errors are shown in lighter colors. 

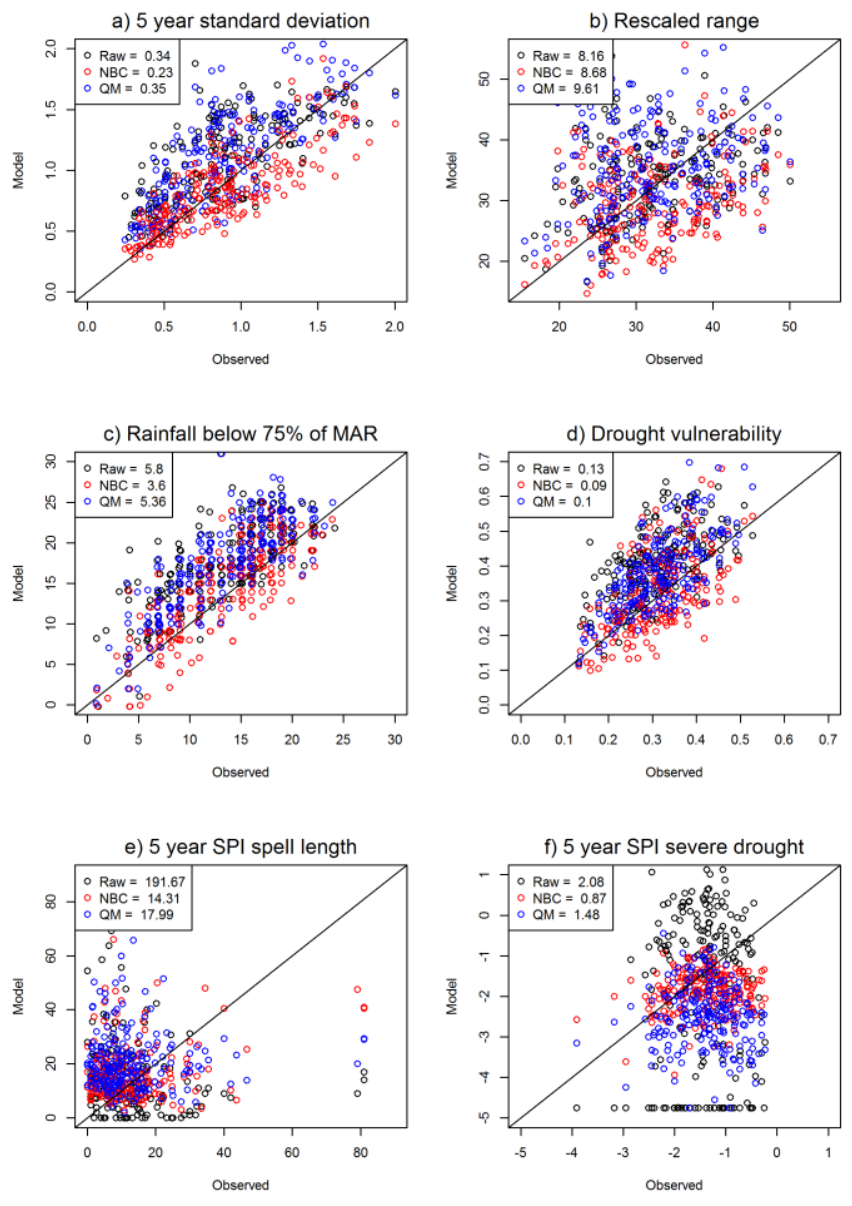

2 Figure 6: Comparison of observed and modelled drought statistics for the CSIRO Mk3.5

3 GCM for a) 5 year rainfall time series standard deviation, b) rescaled range, c) MAR75, d)

4 drought vulnerability, e) SPI 5 year spell length and f) SPI 5 year severe drought threshold.

5 Raw GCM simulations are shown in black, NBC in red and QM in blue. The RMSE of the

6 model estimates is shown in each panel. 

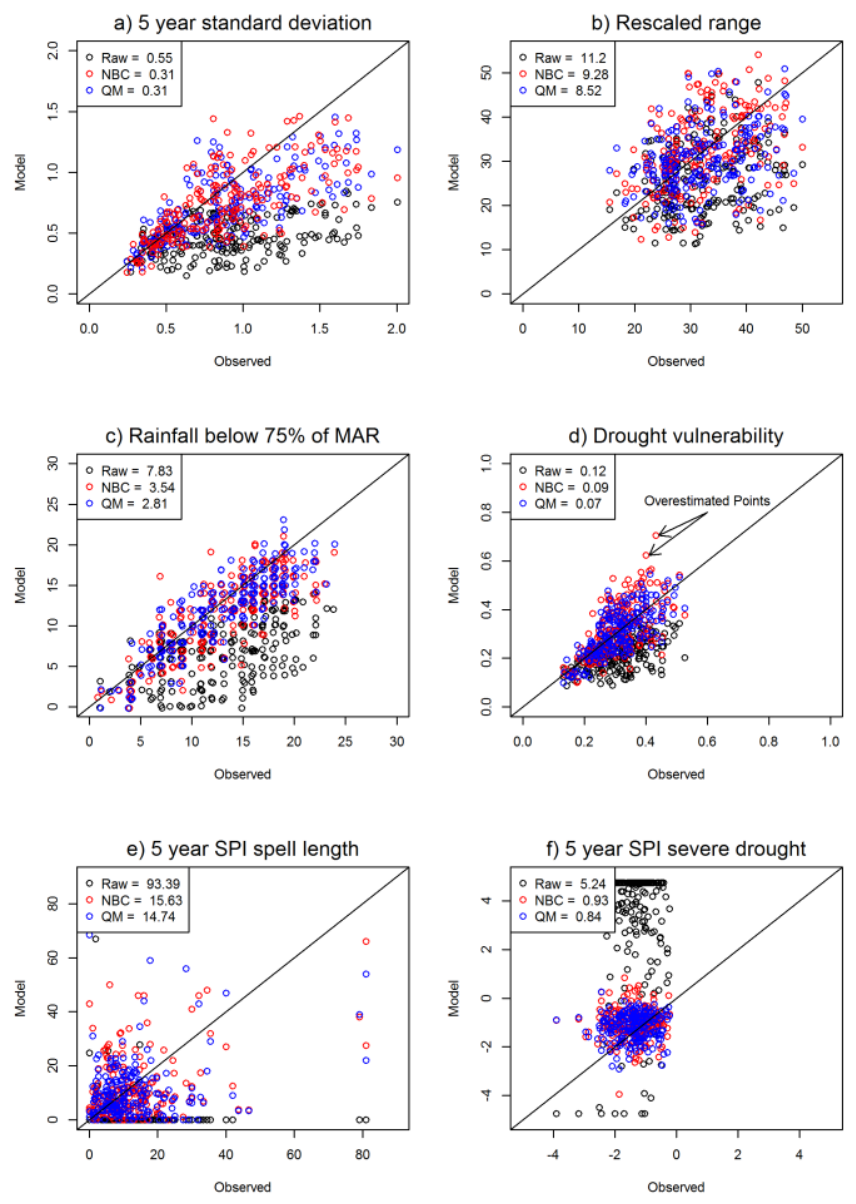

2 Figure 7: As for Figure 6 but showing results for INGV_ECHAM4 
a) NBC Severe Drought

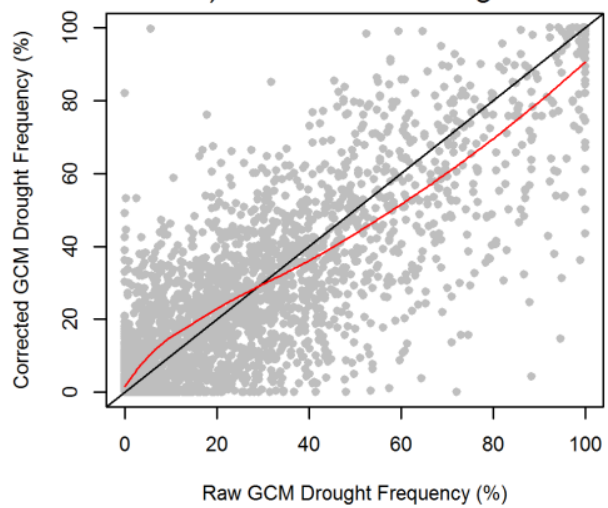

c) NBC Drought Vulnerability

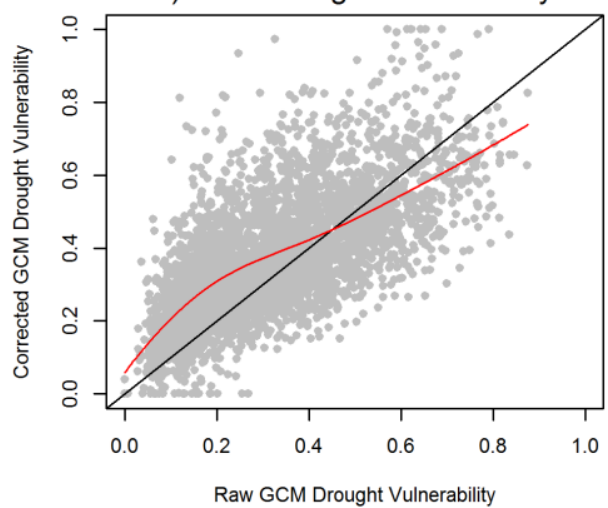

e) NBC MAR75

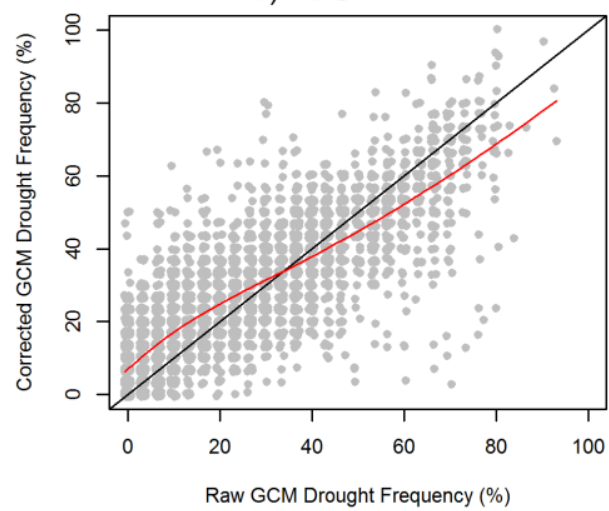

b) Quantile Mapping Severe Drought

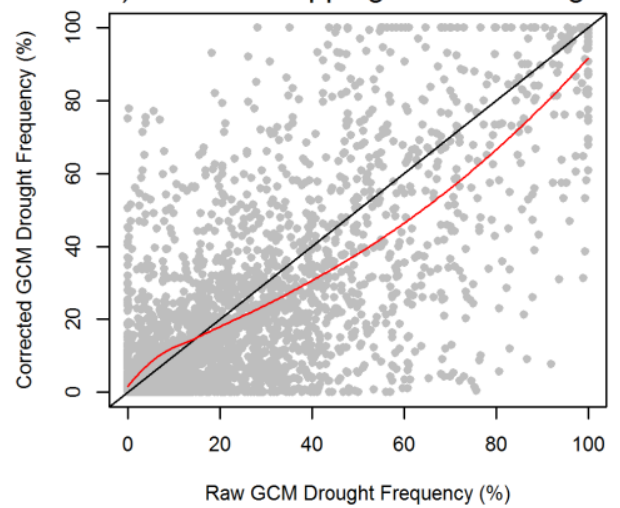

d) Quantile Mapping Drought Vulnerability
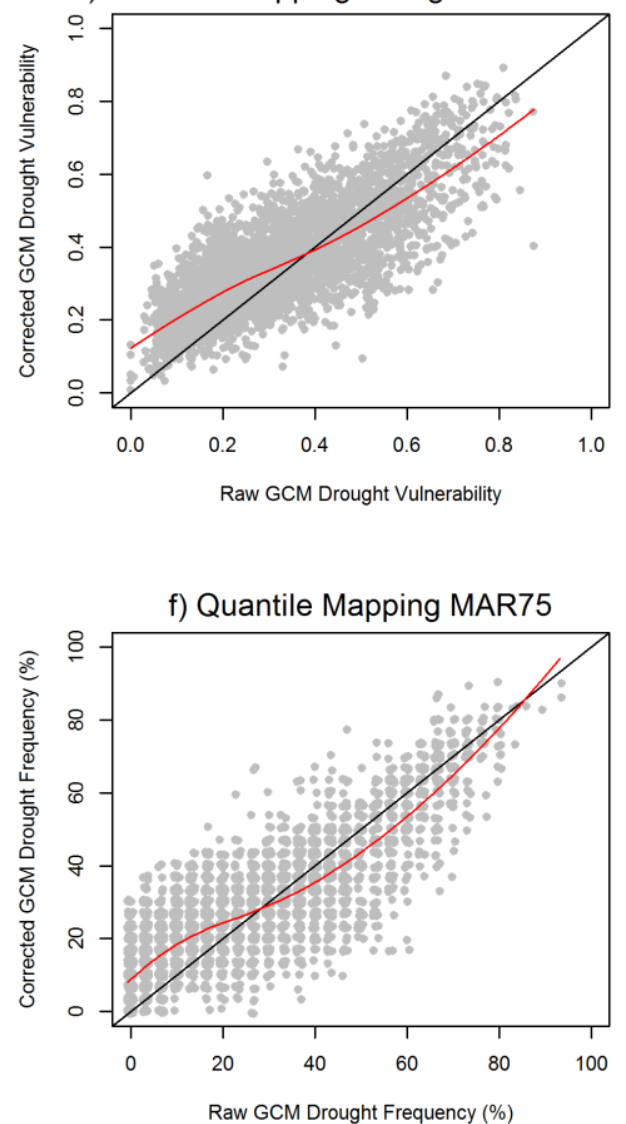

2 Figure 8: Comparisons of raw and bias corrected projections of future drought for all grid

3 cells and all GCMs for 5 year SPI Severe Drought frequency (top row), drought vulnerability

4 (middle row) and MAR75 (bottom row). A local polynomial regression has been fitted in

5 each case to summarize the relationship between raw and bias-corrected estimates. 
a) Raw SPI 5 year Severe Drought

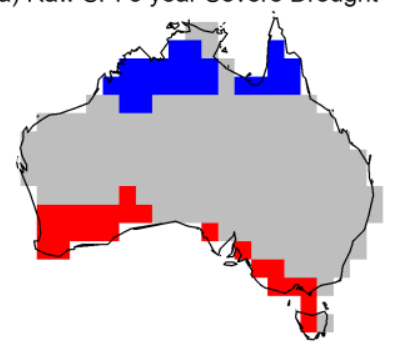

d) Raw Drought Vulnerability

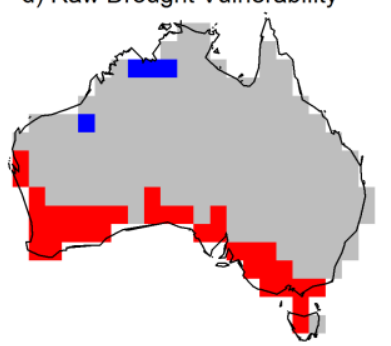

b) NBC SPI 5 year Severe Drought

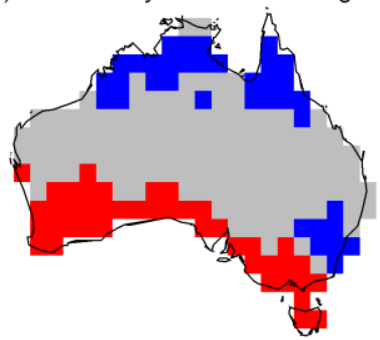

e) NBC Drought Vulnerability

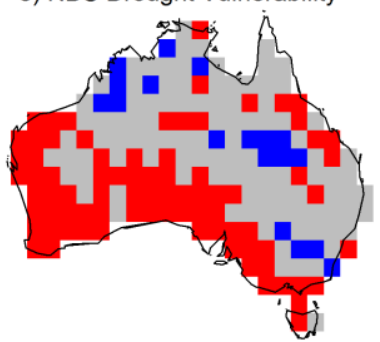

c) QM SPI 5 year Severe Drought

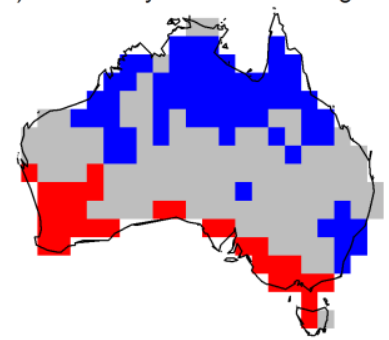

f) QM Drought Vulnerability

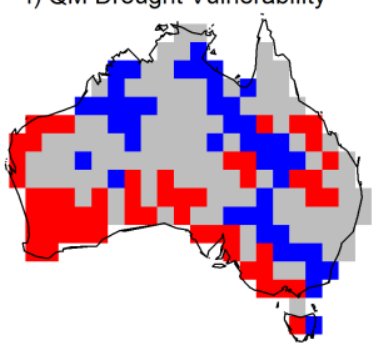

2 Figure 9: Spatial variation of model consensus in future changes in drought frequency for SPI

35 year severe drought (top row) and drought vulnerability (bottom row) for raw, NBC and

4 QM simulations. Areas shown in red (blue) have at least two-thirds of models projecting

5 increased (decreased) drought frequency in the future. Areas shown in grey have limited

6 model consensus on the direction of change in future droughts. 


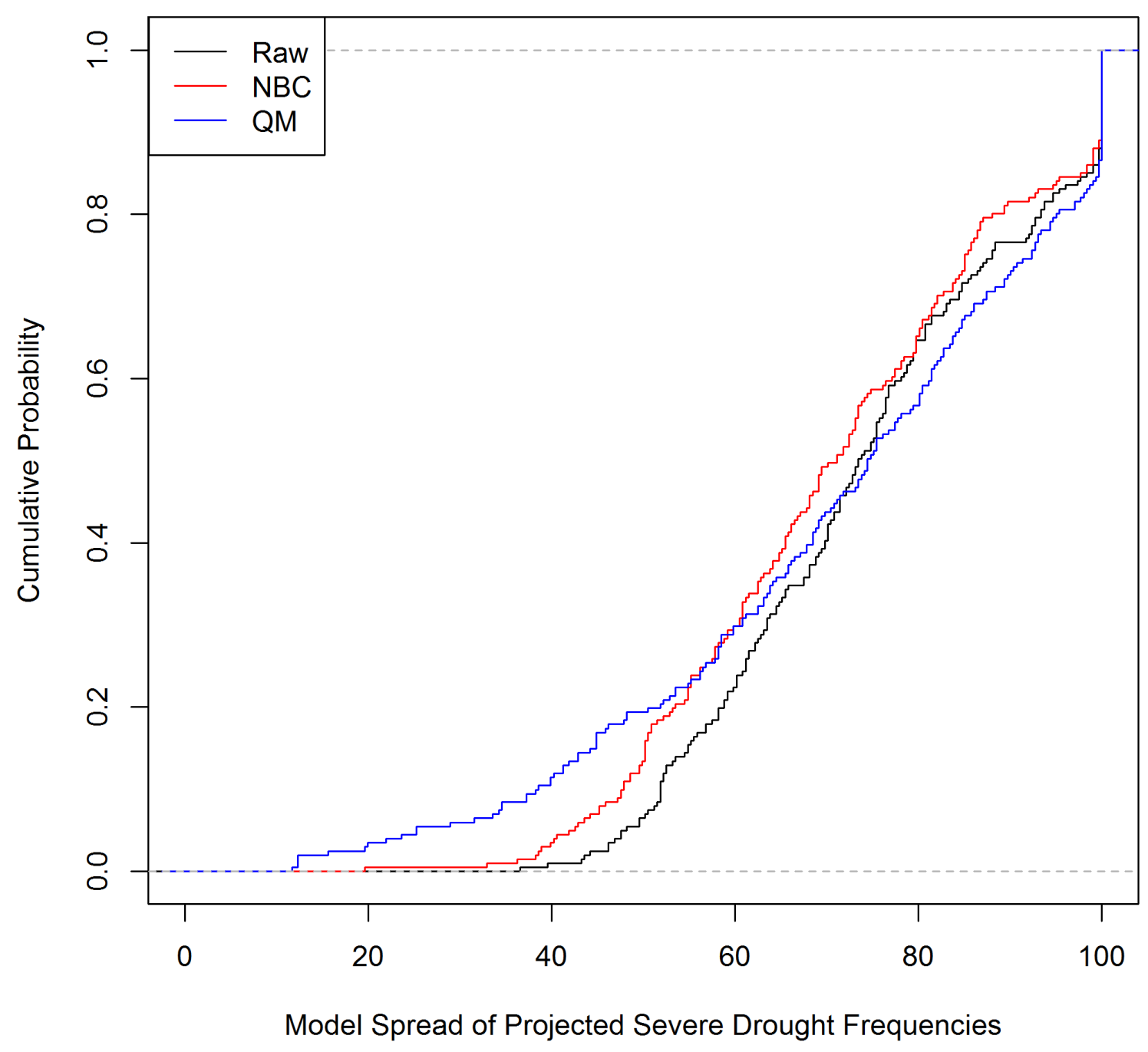

2 Figure 10: Empirical cumulative frequency distributions of the model spread across all GCMs

3 of the future drought frequency (5 year SPI) for raw and bias corrected simulations.

4 Uncertainty in the model projections is smaller when the spread is smaller. 